\title{
An Intersectional Analysis of COVID-19 Unemployment
}

\author{
Armagan Gezici ${ }^{1} \cdot$ Ozge Ozay $^{2}$
}

Received: 3 August 2020 / Revised: 17 October 2020 / Accepted: 16 November 2020 / Published online: 15 December 2020

(C) The Author(s), under exclusive licence to Springer Nature Switzerland AG part of Springer Nature 2020

\begin{abstract}
Using the April 2020 Current Population Survey (CPS) micro dataset, we explore the racialized and gendered effects of the COVID-19 pandemic on the probability of being unemployed. The distribution of the pandemic-induced job losses for women and men or for different racial/ethnic categories has been studied in the recent literature. We contribute to this literature by providing an intersectional analysis of unemployment under COVID-19, where we examine the differences in the likelihood of unemployment across groups of White men, White women, Black men, Black women, Hispanic men, and Hispanic women. As a case of study of the COVID-19 recession, our work engages with the broader empirical literature testing the discrimination theories based on the unexplained gap after accounting for observable characteristics of women, men, and different races/ethnicities and their labor market positions. Controlling for individual characteristics such as education and age, as well as industry and occupation effects, we show that women of all three racial/ethnic categories are more likely to be unemployed compared to men, yet there are substantial differences across these groups based on different unemployment measures. Hispanic women have the highest likelihood of being unemployed, followed by Black women, who are still more likely to be unemployed than White women. We also examine if the ability to work from home has benefited any particular group in terms of lowering their likelihood of unemployment during the pandemic. We find that in industries with a high degree of teleworkable jobs, White women, Black men, and Hispanic men are no longer more likely to be unemployed relative to White men. However, Black women and Hispanic Women still experience a significantly higher probability of job loss compared to White men even if they are employed in industries with highly teleworkable jobs. As we control for both individual and aggregate factors, our results suggest that these differences are not simply the result of overrepresentation of women of color in certain industries and occupations; rather, unobservable factors such as discrimination could be at work.
\end{abstract}

Keywords Unemployment $\cdot$ Race $\cdot$ Gender $\cdot$ COVID-19 $\cdot$ Telework $\cdot$ Intersectionality $\cdot$ Discrimination

\section{Introduction}

Armagan Gezici

agezici@keene.edu

Ozge Ozay

oozay@ fitchburgstate.edu

1 Department of Economics \& Political Science, Keene State College, Keene, NH, USA

2 Department of Economics, History, \& Political Science, Fitchburg State University, Fitchburg, MA, USA

Race and gender disparities in labor market outcomes have been a persistent feature of the US labor markets. The labor market experiences of women and men of different races and ethnicities are reflected in the differences in labor force participation rates, median wages, the occupations, and industries they work in. The intersection of gender and race shapes these experiences heavily to the disadvantage of women and nonWhite race and ethnicities. ${ }^{1}$ Specifically, Latina and Black women have been found to be paid lower wages (Browne

\footnotetext{
${ }^{1}$ Throughout this paper, we will use BLS categories of Whites, African Americans, and Hispanics. African Americans and Blacks, and Hispanics and Latinx will be used interchangeably.
} 
1999), overrepresented in low-paying occupations (Altonji and Blank 1999), ranked low in occupational hierarchies, and lacking job authority (Browne et al. 2001). To explain these outcomes, the feminist literature emphasizes the intersection of race and gender as mutually constituted to maintain social hierarchies (Browne and Misra 2003). Intersectional feminist theorists also suggest that discrimination by employers (Weber 2001) and/or customers and coworkers (Bell and Nkomo 2001) results in and reproduces the social hierarchy matrix by race and gender. Economic theories, on the other hand, often conceptualize race and gender differences in the labor market through disconnected models. In explaining these differences, they focus on individual preferences and skills (human capital) as well as differences in labor market position (industry, occupation, and region) (Altonji and Blank 1999). In empirical applications of these studies, discrimination is taken to be the residual difference that exists in labor market outcomes which cannot be explained by these factors (Altonji and Blank 1999).

The increase in the national unemployment rate in the USA due to the COVID-19 pandemic and social distancing measures, from 4.4 in March 2020 to $14.7 \%^{2}$ in April 2020, has been the most recent example of asymmetrical impacts across different race and gender categories of the labor force. In line with the emphasis of the intersectional approaches mentioned above, the increase in the unemployment rate was particularly prominent for women and non-White races and ethnicities. In January 2020, the unemployment rate was $3.3 \%$ for White men, $2.9 \%$ for White women, $6.1 \%$ for Black men, $5.8 \%$ for Black women, $4.9 \%$ for Hispanic men, and 5.3\% for Hispanic women. By June 2020, the unemployment rate had reached $9.4 \%$ for White men, $10.8 \%$ for White women, $16.6 \%$ for Black men, $14.3 \%$ for Black women, $13.3 \%$ for Hispanic men, and $16.1 \%$ for Hispanic women (BLS 2020). As data became available, a growing literature began to examine the determinants and distributional consequences of pandemicrelated job losses for women and men (Alon et al. 2020; Adams-Prassl et al. 2020) and for different racial/ethnic categories (Montenovo et al. 2020; Fairlie et al. 2020; Cowan 2020). While these studies all agree that women's unemployment increased substantially more than men's during the pandemic, findings on the effects on racial/ethnic groups are not as conclusive, with some finding a large impact for Blacks (Cowan 2020) and others suggesting the impact to be larger for Latinx (Montenovo et al. 2020).

In this paper, we analyze the pandemic-induced unemployment differences by race and gender, as observed in April 2020 CPS data, to examine whether there exists a higher likelihood of becoming unemployed for Black and Hispanic women after controlling for labor force characteristics (education and age), as well as their labor market position (industry,

\footnotetext{
${ }^{2}$ Bureau of Labor Statistics 2020 - Hereinafter BLS
}

occupation, and region). With its empirical framework, our work contributes to the broader economic literature on race and/or gender differentials in labor market outcomes by providing a case study of the differential impact of the COVID19-induced recession. The emphasis put forward by intersectional feminist theorists plays an essential role in our approach. Instead of analyzing group differences of race and gender separately and risking the generalization of White women's unemployment as the experience of women of all races, or disregarding the differences in a Black woman's experience in comparison to a Black man's, we utilize intersectional groups of White men, White women, Black men, Black women, Hispanic men, and Hispanic women to study these differences.

Our analysis reveals a more nuanced picture of the COVID-19 unemployment that has already been labeled as a "she-cession" in the popular press (Gupta 2020). We confirm that women of all three racial/ethnic categories are more likely to become unemployed compared to men, yet there are substantial differences across these groups under different unemployment measures. As expected, the additional disadvantage of women of color is again realized, even after controlling for all individual- and industry-level observable factors, with Hispanic women experiencing the highest likelihood of unemployment, followed by Black women, who are still more likely to be unemployed than White women. We also find that although Hispanic men have a higher probability of losing their jobs compared to White men, this probability is even higher for Black men. Overall, our results clarify the inconclusive findings of other studies about whether Blacks or Latinx are more profoundly affected by the COVID-19induced unemployment.

The recession that began in March 2020 differs greatly from prior recessions, specifically in terms of the industries affected. Within the essential/non-essential classification of industries, some service industries that have traditionally been considered less cyclical came to a complete halt, while some of the typically cyclical manufacturing industries continued to operate. The feasibility of working from home became a crucial determinant of who gets to keep their job, and a number of studies developed measures of the feasibility of working from home for various occupations (Dingel and Neiman 2020). As emphasized by the literature on the differential effects of recessions on the unemployment of different groups, industrial and occupational segregation is an important mechanism that results in asymmetric outcomes. In order to capture these pandemic-specific effects on unemployment, we use measures for the degree of teleworkable jobs in an industry, as well as whether the industry is deemed essential or not. Since employment in industries with more teleworkable jobs can provide shelter from unemployment, we explore if the ability to work from home has benefited Black and Hispanic women by lowering the likelihood of unemployment during the pandemic. 
We find that, even though White women, Black men, and Hispanic men are no longer more likely to be unemployed relative to White men in industries with a high degree of teleworkability, Black women and Hispanic women still experience a significantly higher probability of losing their jobs, even when employed in industries with highly teleworkable jobs.

In the "What We Know About Racial and Gender Gaps in Unemployment Over the Business Cycle" section, we review the economic theories that explain why recessions may result in race and gender disparities in unemployment. This review highlights the importance of occupational and industrial segregation, as well as discrimination, as mechanisms through which different groups disproportionately lose their jobs. We also show that some of the important insights from the literature, such as the lessening of the gender gap in unemployment over time or the relative adverse effect of recessions on men's unemployment, are not necessarily valid for all racial/ethnic groups, which affirms a need for intersectional analysis. In the "Racialized-Gendered Unemployment Under the COVID-19 Recession" section, we review the existing studies of COVID19-related unemployment with a focus on the unemployment of women and people of color. Here, we discuss the studies on the types of jobs and industries with teleworking opportunities against the background of the pandemic and pose the question of whether Black and Hispanic women have benefited from these opportunities. The "Data on COVID-19 Unemployment" section describes the dataset, two different definitions of COVID-19-related unemployment, as well as the characteristics of the unemployed based on these definitions. In the "Regression and Results" section, we present our empirical framework and the results from probit regression, wherein we measure the relative likelihood of unemployment across racial/ethnic-gender categories, given the controlling variables mentioned above. In this section, we also test for the interaction between racial/ethnic-gender categories and the degree of teleworkability in industries. The "Concluding Remarks" section then presents a discussion and concluding remarks.

\section{What We Know About Racial and Gender Gaps in Unemployment Over the Business Cycle}

There are two prominent lines of work in the theoretical literature on race and gender disparities in labor market outcomes: the first focuses on the differences in individual preferences across members of different groups, and the second examines discrimination as the main mechanism through which gender and race disparities emerge (Altonji and Blank 1999). In both strands of the literature, researchers study either race or gender distinctively (Altonji and Blank 1999); here, we broadly review each approach to shed light on the mechanisms through which recessions may result in further disparities in unemployment across different groups.

Frequently deployed to explain gender differentials in labor market outcomes, the first approach argues that preferences for market, non-market work and leisure, and/or particular types of work will be different for women and men (Rosen 1986). This type of self-selection results in occupational and industrial segregation, where women are overrepresented in certain occupations and/or industries. Consequently, the asymmetric impact of recessions across industries and occupations leads to differential employment outcomes for men and women. The main criticism of this approach is that preferences are taken to be exogeneous. Without any exploration of the sources of gendered preferences, this view ignores, for instance, the pre-market gender discrimination in child rearing and/or the educational system (Altonji and Blank 1999).

An alternative argument within this line of work, as argued by Becker (1991), suggests that in a competitive economy, comparative advantage stemming from biological differences determines the time allocation across occupations and among market and non-market work. Models emphasizing human capital also state that investment in valuable marketplace skills will be lower among those who expect to spend less time in the marketplace (Altonji and Blank 1999). As women are expected to have a lower labor force attachment due to disruptions during childbearing years, employers invest less human capital in women, further amplifying the divergence in the human capital of men and women. In addition, women's educational choices might reflect their expectation of lower labor force attachment. Low investment in human capital results in occupational and industrial segregation, which in turn explains the asymmetric impact of recessions on the employment of men and women. However, this approach also has been criticized for emphasizing the role of voluntary choices and ignoring the role of socialization and gender in determining to a certain extent people's choices and preferences (Blau and Winkler 2017).

The comparative advantage approach, coupled with human capital theory, also provides an explanation for racial occupational segregation. Altonji and Blank (1999) state that to the extent that parents in particular occupations provide children with a comparative advantage in these occupations, belowaverage representation of minority groups in managerial jobs may lower the probability that minority youths obtain the skills required to hold these jobs in the future. Likewise, the economic prospects of minorities have dropped when school quality has been lower in neighborhoods disproportionately populated by minorities. These differences in the level of human capital, acquired prior to labor force entry or in-home environment, would not only contribute to racial unemployment disparities but also help partially explain how these disparities change during recessions. In support of this argument, Engemann and Wall (2009) find the role of educational 
attainment in determining job losses across demographic groups to be almost as important as industrial segregation during the Great Recession. Their findings show Black men, for whom average education tends to be lower than for Black women or Whites, saw the largest decrease in employment.

In studies emphasizing the differences in human capital and group preferences, occupational and industrial segregation emerge as the distinctive channel through which recessions have disproportionate employment consequences for different groups. Changes in occupational and industrial segregation patterns over time are also partially responsible for the changes in the unemployment gap between men and women. Especially since the 1980s, women's unemployment has displayed a less cyclical trend than that of men, resulting in lower unemployment rates for women during recessions. Hoynes et al. (2012), for example, find that the impact of the Great Recession was felt most strongly for men in general, and Black and Hispanic workers specifically, due to the variation in cyclicality across different industries. However, human capital and comparative advantage are not the only factors resulting in occupational segregation. Social norms regarding appropriate occupations may differ between groups; legal and institutional constraints may limit access of certain groups to some occupations. Another possibility concerns severe employer discrimination in one industry or occupation than in another.

Indeed, discrimination is at the core of the second main approach mentioned in the literature on race and gender disparities in labor market outcomes. These models are based on what Becker calls "a taste for discrimination," i.e., having a prejudice against a group of people by employers, coworkers, and customers (Altonji and Blank 1999). The empirical models testing the role of discrimination in causing different outcomes across gender/race/ethnicity use the control variables observable as labor supply characteristics and a dummy variable for group identity. Then, the unexplained component of the differential outcome is identified as discrimination. The implication of discrimination theories for cyclical gendered and/or racial unemployment disparities goes beyond occupational and industrial segregation channels. Regardless of industry, this approach hypothesizes that during expansions, the gendered and/ or racial unemployment differential would be reduced as employers find discrimination costlier. Likewise, as argued by Couch and Fairlie (2010), during recessions, a discriminating employer can lay off equally qualified Blacks and not face economic costs for doing so. There is indeed evidence to support this in empirical literature: the seminal work by Richard Freeman (1973) about racial patterns of labor market status from 1948 to 1972 shows that the level of employment for Blacks was more volatile than for Whites, and the unemployment rate for Blacks rises more than for Whites when the economy weakens, suggesting a "last in, first out" pattern of Black employment over the business cycle.
However, the empirical evidence for the "last in, first out" hypothesis does not seem to be conclusive for all time periods and racial groups. Bradbury (2000) does find evidence that disadvantaged groups experience larger percentage-point declines in unemployment rates than their counterparts in advantaged groups during the expansionary periods within 1972-1990. In testing this hypothesis for the period of 1989-2004, Couch and Fairlie (2010) find considerable evidence that Black men are the first to be fired during downturns, and no evidence to confirm a last-hired claim. Couch et al. (2016) test the hypothesis for the period of 1996-2012 and find both Blacks and Hispanics to be fired first. For 19762016, Cajner et al. (2017) find that both Black and Hispanic men and women are affected by recessions relatively more than Whites on average. They show that whereas the Hispanic/White unemployment gap can largely be explained by differences in educational attainment, the more substantial Black/White unemployment gap cannot be explained by observable characteristics. They conclude that personal and institutional discrimination can be responsible from the unexplained component for the unemployment gap for Blacks.

As the majority of the empirical literature on racial and gender disparities in labor market outcomes has focused on differences for either race or gender groups, there has been a recent call for intersectional analysis. Grown and Tas (2011), for instance, caution against labeling the Great Recession as a "man-cession," hence undermining its adverse influence on women, which can be identified through the examination of multiple labor market indicators and incorporation of race/ ethnicity into the analysis. Among the studies on the Great Recession, Engemann and Wall (2009) is another example noting that the differences in unemployment across racial categories are intertwined with differences across other categories, such as gender and education. As another example, Kondo (2015) studies the intersectional differential effects of unemployment at labor market entry on subsequent wages. Paul et al. (2018) examines the gender and race wage gaps and demonstrates that, in addition to discrimination based solely on the singular identities such as race and gender, some groups face compounded nonlinear discriminatory penalties, which highlights the importance of intersectional analysis.

A cursory look at the evolution of unemployment rates in Fig. 1 for combined racial/ethnic/gender categories over the last two decades is sufficient to elucidate the need for studying unemployment differentials across these groups at the intersection of race and gender. For example, the disappearance of the gender gap in unemployment seems only valid for White men vs White women, while the unemployment gap for Black men and Black women displays a different pattern regardless of business cycle phases. With the exception of 2006, Black men's unemployment rate has been persistently higher than Black women's. Conversely, Hispanic women's unemployment has been higher than Hispanic men's for all but the 4 years of the 
Fig. 1 Unemployment rate of race/ethnicity-gender groups
Unemployment Rate of Race/ethnicity-Gender groups

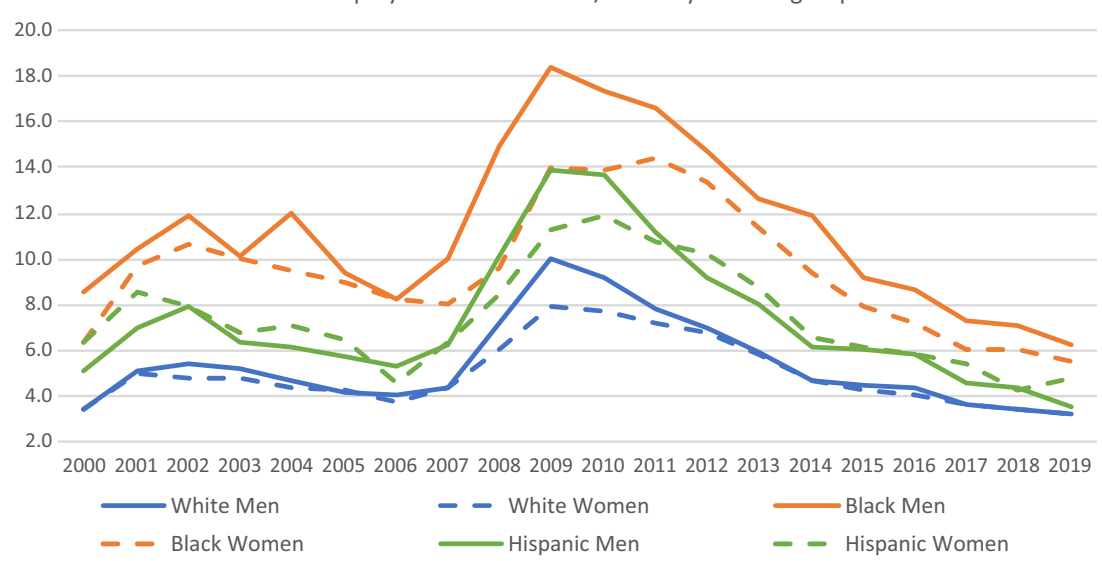

Great Recession. While men's unemployment across race and ethnicity groups is higher than women's during the Great Recession, the change is the most dramatic for Blacks in terms of percentage points. The gap between the unemployment rates for White men and White women reaches $2.1 \%$ in 2009, the highest in the last 30 years (from almost zero in 2006). For Black men and women, the same gap is $4.4 \%$ in 2009 , indicating that the Great "man-cession" was more severely felt by Black men than White men. A motivation for our paper is to explore whether similar asymmetries exist for different racial/ ethnic categories under the COVID-19 recession (to which the term "she-cession" has been applied).

In this paper, we examine the differential impact of the COVID-19 recession on unemployment by focusing on the intersection of race and gender with a special emphasis on Black and Hispanic women's unemployment probabilities in relation to other groups. Inspired by the intersectional feminist studies, our work contributes to the empirical economic literature that attributes discrimination to group differences - after accounting for all the observable labor market characteristics - by providing a case study of unemployment during the COVID-19-induced recession. Even though our current methodology is not able to determine the qualitative reasons for the unique experience of minority women, we explicitly attempt to capture the racialized and gendered outcomes of COVID-19 on unemployment by controlling for variables that exhaust the potential explanations related to labor supply qualifications and industrial or occupational segregation.

\section{Racialized-Gendered Unemployment Under the COVID-19 Recession}

Within the rapidly evolving literature focusing on COVID-19 and labor market outcomes, a handful of studies examine the differences in the unemployment experiences of demographic groups. In this section, while reviewing their findings, we also discuss the unique characteristics of the current recession with consequences for the unemployment of different groups.

One conclusive finding of these studies is that unlike a "regular" recession, social distancing policies have had a larger effect on women's unemployment (Alon et al. 2020). Adams-Prassl et al. (2020) present similar findings for both the US and the UK: women and workers without a college degree are significantly more likely to have lost their jobs. Using February and April CPS surveys, Cowan (2020) shows that, conditional on being employed in February, women are less likely than men, and all racial minorities are less likely than Whites, to be employed in April. And controlling for occupation and industry, the effect is particularly large for Black workers (3.5\% more likely). Fairlie et al. (2020), on the other hand, suggest that compared with the Great Recession, Blacks did not experience a disproportionately large increase in unemployment relative to Whites, while Hispanic workers did. Similarly, Montenovo et al. (2020) find large increases in recent unemployment among women, Hispanics, and younger workers. While our work relates to these studies, by using intersectional categories of race/ ethnicity and gender, we are able to examine whether the disproportionate likelihood of unemployment for women found in these works is an equally shared experience for White, Black, and Hispanic women. Similarly, we address the question of whether there are gendered differences within minority groups in terms of the disproportionate unemployment effects reported above.

As suggested by the theories reviewed in the "What We Know About Racial and Gender Gaps in Unemployment Over the Business Cycle" section, the asymmetric impact of the COVID-19 recession on various industries and occupations has been identified as the primary factor determining the gendered and racialized impact of unemployment. However, industries and occupations affected during the current recession partly differ from those affected during the previous recessions. With essential/non-essential classification of industries, some service industries which are typically considered less 
cyclical came to a complete halt, while certain typically cyclical manufacturing industries continued to operate. In their study of "essential" industries (based on executive orders from California and Maryland), McNicholas and Poydock (2020) use a CPS database to show that women make up the majority of essential workers in healthcare $(76 \%)$ and government- and community-based services (73\%), whereas people of color make up the majority of essential workers in food and agriculture $(50 \%)$ and in industrial, commercial, and residential facilities and services (53\%). Using data from the American Community Survey for the period of 2014-2018 Rho et al. (2020) show that women and people of color are overrepresented in workforce employed in "front-line" industries (e.g., grocery stores, public transit, and healthcare). Considering the fact that most workers in essential or "front-line" industries have kept their jobs (as confirmed by Montenovo et al. 2020), the higher likelihood of unemployment reported for women and minorities presents a perplexing question. In our empirical analyses of the determinants of COVID-related unemployment, we control for essential/non-essential industry classification based on the state of Delaware's criteria, as done by Fairlie et al. (2020). ${ }^{3} 7$ To control for the disproportionate effects of the COVID-19 recession on different segments of the economy, we also include occupation and industry categories.

Another highly emphasized determinant of pandemic-related unemployment has been whether workers can work from home. Among the growing number of studies measuring the feasibility of working from home, Adams-Prassl et al. (2020) show that workers who report they can do a high share of tasks from home are substantially less likely to report losing their jobs due to the COVID-19 outbreak in both the US and the UK. Dingel and Neiman (2020), who use the occupational descriptions from the Occupational Information Network (O*NET) surveys to designate any given occupation as able or unable to be performed at home, estimate that $37 \%$ of jobs in the USA "can plausibly be performed from home." Based on their occupational classification, they also show that there is significant variation in the share of teleworkable jobs across industries. As expected, most jobs in finance, corporate management, and professional and scientific services could plausibly be performed at home, whereas very few jobs in agriculture, hotels and restaurants, or retail can be. ${ }^{5}$ Using survey data, Brynjolfsson et al. (2020) find the fraction of

\footnotetext{
$\overline{3}$ The Delaware's full list can be accessed at the link https://coronavirus. delaware.gov/resources-for-businesses/.

${ }^{4}$ As they note in their paper, this measure neglects many characteristics that would make working from home difficult. Therefore, it is an upper-bound on what might be feasible. Dingel and Neiman (2020) develop an alternative measure based on individual introspection of different occupations, which leads to a relatively conservative estimate of teleworkable jobs.

${ }^{5}$ While beyond the scope of the paper, it is important to note that teleworkability has many other determinants than the nature of tasks accomplished on the job. Firm-level differences in ability to invest and train employees and spatial differences in infrastructure are among these reasons.
}

workers who switched to working from home by May 2020 to be about $35.2 \%$, not far off of Dingel and Neiman's (2020) estimate. Likewise, Bartik et al. (2020) find that the Dingel and Neiman's classification of work-from-home capacity is indeed a strong predictor of industry-level variation in remote workability during the pandemic. Dingel and Neiman's (2020) classification has been influential both in research and in practice as a way to understand the potential for remote work across industries and demographic groups. Using this measure, Yasenov (2020) shows that lower-wage workers are up to three times less likely to be able to work from home than higher-wage workers. Those with lower levels of education, younger adults, ethnic minorities, and immigrants are also concentrated in occupations that are less likely to be performed from home. Whereas the opportunity to telework would reduce the likelihood of unemployment, to the extent that women and minorities are underrepresented in these industries, high teleworkability might not provide any benefit to these groups. Having shown that a lower share of women are employed in highly teleworkable occupations in comparison to occupations with a low degree of teleworkability, Alon et al. (2020) suggest that "more women potentially face loss of employment" in these less teleworkable jobs.

We use Dingel and Neiman's (2020) measure of the share of teleworkable jobs in an industry as an industry-specific determinant of unemployment. On the surface, there seems to be a negative correlation between the share of employment by people of color and the measure of teleworking opportunities in an industry. Almost all industries in which Blacks and Latinx are overrepresented have a lower-than-average share of teleworkable jobs. ${ }^{6}$ As for the industry-specific shocks induced by the COVID-19 pandemic, more layoffs are likely to occur in industries with fewer teleworkable jobs, leading to a higher likelihood of unemployment for Blacks and Latinx. This pattern is not as clear for women, since women are also overrepresented in education and social assistance, both being industries with higher-than average teleworkable jobs. This ambiguity confirms the need for intersectional analysis of the differentials in the likelihood of unemployment during the pandemic.

\section{Data on COVID-19 Unemployment}

We use April 2020 CPS survey data to conduct our analysis of the impact of the COVID-19 pandemic on the probability of being unemployed in the USA and how race and gender

\footnotetext{
${ }^{6}$ Based on the BLS Labor Force Statistics in 2019, men made up 47\%, Whites $77.8 \%$, African Americans 12.7\%, and Latinx 18\% of the US labor force. Industries included here are those with highest share of employment for women, Black, and Latinx among 73 industry categories (based on NAICS 2 and NAICS 3 classification) that we matched to Dingel and Neiman's measure of the share of teleworkable jobs in an industry. We used the relatively conservative measure of teleworkability, which was described in footnote 13 . The unweighted average of teleworkability index for all 73 industries in our sample is $30 \%$.
} 
contribute to this probability. Most of the states which implemented lockdown measures began to do so in March 2020, so April is the first month to fully display the effects of COVID19 on the labor market. The reference period is April 12-18, 2020. We use a narrow and a broad measure of COVID-19 unemployment in order to account for a misspecification issue that BLS warns users of CPS with the unemployment data collected in March and April 2020, which leads to an underestimation of the national unemployment rate. ${ }^{7,8}$

1) Narrow COVID-19 unemployment: Individuals, identified as "job losers on layoff" (BLS category), whose unemployment duration is up to and including 4 weeks, are included in this category. This is a rather conservative definition of unemployment, which results in 10.5 million unemployed due to COVID-19.

2) Upper-bound COVID-19 unemployed: In addition to the individuals in the narrow category, we include "other job losers" whose unemployment duration is up to and including 4 weeks, those with ending temporary jobs whose unemployment duration is up to and including 4 weeks, and those who were "employed-but-absent" due to "other" reasons in the reference week that BLS identified as misclassified. This measure results in 18.6 million unemployed.

Table 1 presents a racial/ethnic-gender snapshot of the pool of COVID-19 unemployed based on the narrow definition of unemployment. The table shows that $26 \%$ percent of the unemployed are White men and 29\% are White women. Compared to the shares of White men and White women in the labor force ( $44 \%$ and $38 \%$, respectively), these figures confirm that Whites are underrepresented among the unemployed. Similarly, the fact that $55 \%$ of the unemployed are women, as compared to women making up $49 \%$ of the labor force, signals the overrepresentation of women among the unemployed. Age and education levels are among the other noteworthy COVID-19-unemployment characteristics: relatively younger people aged 21-30 make up the largest age group $(27 \%)$, and, in terms of educational attainment, high school graduates represent the largest share of the unemployed at $55.3 \%$.

In terms of occupational distribution, we see that $14 \%$ of the unemployed are in food preparation and related

\footnotetext{
${ }^{7}$ The BLS instructed surveyors to code those out of work due to the epidemic as recently laid off or unemployed, but surveyors appeared to code at least some of them in the employed-but-absent category. According to the estimates provided by BLS, out of 11.5 million workers classified as employed-butabsent in April 2020, around 7.5 million should have been classified as unemployed. If these people were to be coded as unemployed, the resulting unemployment rate for April would be $19.2 \%$, compared with the official estimate of $14.4 \%$ (not seasonally adjusted).

${ }^{8}$ We base our analysis on working age population (15-64). Individuals who report themselves as out of the labor force are excluded from this analysis.
}

Table 1 Cross tabulation of race and gender of COVID-19 unemployed

\begin{tabular}{llll}
\hline $\begin{array}{l}\text { Race/ } \\
\text { ethnicity }\end{array}$ & Men & Women & Total \\
\hline White & 0.26 & 0.29 & 0.55 \\
Black & 0.07 & 0.07 & 0.14 \\
Hispanic & 0.12 & 0.11 & 0.23 \\
Other & 0.04 & 0.04 & 0.08 \\
Total & 0.49 & 0.51 & 1 \\
\hline
\end{tabular}

$\mathrm{F}(2.96,9214.62)=2.18, p=0.09$.

occupations, followed by $11.3 \%$ in sales and related occupations. A closer look reveals that from among food preparation and related occupations, $24.3 \%$ are waiters and waitresses, and $20.7 \%$ are cooks. $41.5 \%$ of sales and related occupations are retail salespersons, and $20.9 \%$ are cashiers. In terms of the industrial distribution of the unemployed, we see that leisure and hospitality comes first at $22 \%$; educational and health services follow at $17.5 \%$; and wholesale and retail trade is a close third at $15.8 \%$. Agriculture, mining, public administration, information, and financial activities are among the sectors with lowest numbers of unemployed (less than $2 \%$ ).

\section{Regression and Results}

We use the April 2020 CPS micro data to examine how the intersection of race/ethnicity and gender contribute to the probability of being unemployed due to the COVID-19 pandemic in the US labor market. In our analysis, we use both narrow and upper-bound unemployment measures (as previously defined). In addition to race/ethnicity gender, we include labor supply characteristics such as age and educational attainment as control variables that might affect an individual's probability of becoming unemployed. We use control variables to capture the differential impact of the COVID-19 recession on different sectors and occupations, as well as the different responses of the state governments across different regions. Finally, we include industry-specific essential/nonessential distinctions made by most state governments and the share of teleworkable jobs in industries among control variables with potential impact on the probability of unemployment.

Our benchmark model takes the following form:

$$
\operatorname{Prob}(X)=\Phi\left(\beta^{\prime} X+u\right)
$$

where,

unemp $_{\mathrm{i}}=\left\{\begin{array}{c}1 \text { if the individual is unemployed due to COVID-19 } \\ 0 \text { otherwise }\end{array}\right.$ 
$\Phi$ is the standard normal cumulative distribution and $X$ is the vector of following independent variables:

- Variable showing the race/ethnicity-gender intersection (six categories of White men, White women, Black men, Black women, Hispanic men, Hispanic women)

- Control variables: age and square of age, educational attainment (four categories of less than high school or high school, associate degree, college degree, advanced degree), variable for the degree of teleworkability in an industry expressed as percentage of jobs that can be worked from home, a dummy variable indicating whether the industry is essential or not, variable for 23 occupations, ${ }^{9}$ variable for 14 sectors, ${ }^{10}$ variable for four regions (Northeast, Southwest, Midwest, West). ${ }^{11}$

$\beta^{\prime}$ is the parameter estimates, and $u$ is the random error term. The parameters of particular interest are those of the "race/gender" variable as they capture the disproportionate effect estimates of COVID-19 unemployment on various intersectional groups. Table 2 shows the summary statistics for the variables.

Table 3 shows the marginal effects from the probit regression results for both narrow and upper-bound unemployment measures. $^{12}$

Compared with White men, all race/ethnicity-gender groups have a higher probability of being unemployed, and the coefficients are statistically significant in both models 1 and 2. Furthermore, in both specifications, the probability of being unemployed is higher for women in each race/ethnicity category. As expected, the largest probability of unemployment in comparison to that of White men is for Hispanic

\footnotetext{
9 The occupational categories are management occupations, business and financial operations, computer and mathematical science, architecture and engineering occupations, life, physical and social science, community and social service occupations, legal occupations, education, training and library occupations, arts, design entertainment and sports, healthcare practitioner and technicians, healthcare support occupations, protective service occupations, food preparation and serving-related occupations, building and grounds cleaning occupations, personal care and service occupations, sales and related occupations, office and administrative support occupations, farming, fishing and forestry occupations, construction and extraction occupations, installation, maintenance and repair occupations, production occupations, transportation and material moving and armed forces.

${ }^{10}$ The categories are agriculture, mining, construction, manufacturing, wholesale and retail trade, transportation and utilities, information, financial activities, professional and business services, educational and health services, leisure and hospitality, other services, public administration, and armed forces.

11 The CPS dataset does provide more comprehensive lists of occupations and industries defined at more detailed level. However, to prevent a potential incidental parameter problem in nonlinear models with group effects, such as occupations, industries, and regions we use here, we limited ourselves to the current detail levels. Introducing these effects with higher detail level would increase the number of parameters to levels with insufficient number of observations in some cases.

${ }^{12}$ Logit and OLS regression estimations of the benchmark model also give similar results.
}

women, followed by Black women (in both models). For Hispanic women, we see that holding these multiple identities increases the probability of unemployment by $5 \%$ compared with White men (using the upper-bound unemployment definition). The fact that Black women and Hispanic women experience the highest probability controlling for labor supply characteristics and labor market positions including COVID19-specific variables suggests that already existing gendered and racial inequalities are reinforced by the COVID-19 pandemic as intersectional feminists would claim. Comparing narrow and upper-bound unemployment results shows that the probabilities from the latter are always higher for each racial/ethnic-gender group. That the smallest discrepancy between the results from narrow and upper-bound unemployment measures is for White women might suggest that the misclassification of unemployment is most predominant for people of color.

As expected, unemployment probability decreases with higher educational attainment, yet only after a college degree, an associate degree does not insulate one from being unemployed compared with high school graduates. ${ }^{13}$ Also, as expected, the probability of unemployment is lower for essential industries. Based on the upper-bound definition of unemployment, the likelihood of becoming unemployed seems to drop by $10 \%$ in essential industries compared to those classified as non-essential. Finally, the teleworkability variable also has a negative marginal effect as expected: as the percentage of jobs that can be done from home in an industry increases, the probability of being unemployed falls.

Given that being employed in an industry with more teleworkable jobs can lead, on average, to a lower probability of being unemployed, we next explore whether this advantage is enjoyed by all race/ethnicity-gender categories uniformly. To do so, we incorporate an interaction term of race/ethnicity gender and the degree of teleworkability to models 1 and 2 . Table 4 shows the marginal effects of the race/ethnicitygender intersection for the highest level of teleworkability in our dataset.

The marginal effects in Table 4 show that even when the share of teleworkable jobs is at a maximum in an industry, the unemployment probability for Black women and Hispanic women is higher than that of White men regardless of unemployment definition. The disproportionate likelihood is quite sizeable based on the upper-bound unemployment measure: Black women are $6 \%$ more likely to be unemployed than White men, and Hispanic women are $7 \%$ more likely to be

\footnotetext{
${ }^{13}$ When we do not control for occupation or industry category, we see that the coefficient of educational attainment category of associate degree becomes significant. Hence, we can state that occupational distribution overlaps with educational attainment for lower educational attainment categories, in the sense that those who have a higher unemployment probability are concentrated in occupational categories that employ relatively lower educational attainment than a college degree.
} 
Table 2 Summary statistics

\begin{tabular}{llllll}
\hline Variable & Mean & St. deviation & Min & Max & Type \\
\hline Unemployment $_{\text {narrow }}$ & 0.05 & 0.22 & 0 & 1 & Dummy \\
Unemployment $_{\text {upper-bound }}$ & 0.09 & 0.28 & 0 & 1 & Dummy \\
Race/gender $_{\text {Teleworkability }}^{2.63}$ & 1.70 & 1 & 6 & Categorical \\
Occupation $_{\text {Sector }}^{33.7}$ & 24.7 & 1.8 & 88.04 & Continuous \\
Education & 11.8 & 6.9 & 1 & 23 & Categorical \\
Age & 7.8 & 3.07 & 1 & 14 & Categorical \\
Essential & 1.89 & 1.11 & 1 & 4 & Categorical \\
Region & 39.7 & 14.15 & 15 & 64 & Continuous \\
Sample size & 0.74 & 0.43 & 0 & 1 & Dummy \\
\hline
\end{tabular}

Individuals are weighted using composited final monthly weights provided by the BLS

unemployed than White men within industries that have the highest degree of teleworkability. Although smaller, a significant disproportionate likelihood of unemployment also exists for Hispanic men, but only based on the upper-bound
Table 3 Probit marginal effects from benchmark model

\begin{tabular}{|c|c|c|c|}
\hline & & Model 1 & Model 2 \\
\hline \multirow{10}{*}{$\begin{array}{l}\text { Race/gender } \\
\text { (reference category: White men) }\end{array}$} & White women & $\begin{array}{l}\text { Unemployment }_{\text {narrow }} \\
0.024^{* * *}\end{array}$ & $\begin{array}{l}\text { Unemployment } \\
0.028^{* * *} *\end{array}$ \\
\hline & & $(0.004)$ & $(0.005)$ \\
\hline & Black men & $0.016^{* *}$ & $0.034 * * *$ \\
\hline & & $(0.008)$ & $(0.01)$ \\
\hline & Black women & $0.028 * * *$ & $0.044 * * *$ \\
\hline & & $(0.008)$ & $(0.01)$ \\
\hline & Hispanic men & $0.010^{*}$ & $0.023 * * *$ \\
\hline & & $(0.005)$ & $(0.007)$ \\
\hline & Hispanic women & $0.033 * * *$ & $0.053 * * *$ \\
\hline & & $(0.007)$ & $(0.009)$ \\
\hline \multirow{6}{*}{$\begin{array}{l}\text { Education } \\
\text { (reference category: less than } \\
\text { high school or high school) }\end{array}$} & Associate degree & -0.003 & -0.004 \\
\hline & & $(0.005)$ & $(0.007)$ \\
\hline & College & $-0.015^{* * *}$ & $-0.035^{* * *}$ \\
\hline & & $(0.004)$ & $(0.006)$ \\
\hline & Advanced degree & $-0.04 * * *$ & $-0.071 * * *$ \\
\hline & & $(0.005)$ & $(0.007)$ \\
\hline \multirow[t]{2}{*}{ Teleworkability } & & $-0.0005^{* * *}$ & $-0.0006^{* * * *}$ \\
\hline & & $(0.0001)$ & $(0.0001)$ \\
\hline \multirow[t]{2}{*}{ Essential } & & $-0.068^{* * *}$ & $-0.10^{* * *}$ \\
\hline & & $(0.005)$ & $(0.006)$ \\
\hline \multicolumn{4}{|l|}{ Other control variables } \\
\hline Age & & Yes & Yes \\
\hline Age squared & & Yes & Yes \\
\hline Region & & Yes & Yes \\
\hline Occupation & & Yes & Yes \\
\hline Sector & & Yes & Yes \\
\hline Sample size & & 34,652 & 34,968 \\
\hline
\end{tabular}

The dependent variable for model 1 is narrow unemployment $(0,1)$ and for model 2 is upper-bound unemployment $(0,1)$. The sample for model 1 is composed of those who are unemployed by narrow definition and employed workers. The sample for model 2 is composed of those who are unemployed by upper-bound definition and employed workers. Standard errors are in parentheses. All regressions use composited final monthly weights provided by the BLS

$$
\begin{aligned}
& * p<0.1 \\
& * * p<0.05 \\
& * * * p<0.01
\end{aligned}
$$


Table 4 Marginal effects at maximum level of teleworkability
Probit regression marginal effects when teleworkability $=88.1$

\begin{tabular}{llll}
\hline & & Model 3 & Model 4 \\
& & Narrow unemployment & Upper-bound unemployment \\
Race/ethnicity and gender & White women & 0.001 & -0.006 \\
(reference category: White men) & & $(0.007)$ & $(0.01)$ \\
& Black men & 0.024 & 0.039 \\
& & $(0.018)$ & $(0.03)$ \\
& Black women & $0.04^{* *}$ & $0.06^{* * *}$ \\
& & $(0.019)$ & $(0.023)$ \\
& Hispanic men & 0.002 & $0.044^{*}$ \\
& & $(0.015)$ & $(0.022)$ \\
& Hispanic & $0.05^{* * *}$ & $0.07 * * *$ \\
Wontrol variables & $(0.017)$ & $(0.021)$ \\
Age & & & \\
Age squared & & Yes & Yes \\
Education & Yes & Yes \\
Occupation & Yes & Yes \\
Sector & Yes & Yes \\
Region & Yes & Yes \\
Essential & Yes & Yes \\
Sample size & Yes & Yes \\
\hline
\end{tabular}

The dependent variable for model 3 is narrow unemployment $(0,1)$ and for model 4 is upper-bound unemployment $(0,1)$. The sample for model 3 is composed of those who are unemployed by narrow definition and employed workers. The sample for model 4 is composed of those who are unemployed by upper-bound definition and employed workers. Standard errors are in parenthesis. All regressions use composited final monthly weights provided by the BLS

$$
\begin{aligned}
& * p<0.1 \\
& * * p<0.05 \\
& * * * p<0.01
\end{aligned}
$$

unemployment measure. Finally, the higher likelihood of unemployment that White women and Black men were previously shown to have experienced relative to White men seems to disappear if they are employed in industries with highly teleworkable jobs. The top five industries with the highest share of teleworkable jobs are in the information and the finance and insurance sectors of the economy. Being employed in these sectors seems to have insulated White women from the disproportionate unemployment effects of the COVID-19 recession.

\section{Concluding Remarks}

Our analysis shows that controlling for labor supply characteristics, geographical regions, occupations, sectors of the economy, essential/non-essential classification, and the degree of teleworkability of industries, women and minorities have been disproportionately affected by COVID-19 in terms of job losses. While we introduce a more comprehensive framework with these control variables, our findings overall are in line with the recent literature on the current recession's initial effects on the unemployment of women and minorities. As a case of study of the COVID-19 recession, our work is a contribution to the empirical literature testing the discrimination theories based on the unexplained gap after accounting for observable characteristics of women, men, and different races/ethnicities and their labor market positions. Furthermore, informed by the feminist theorists, who emphasize the role of socialization and the combination of race and gender in creating unique experiences in the labor market, we also contribute to the smaller strand of literature that calls for an intersectional lens to analyze the labor market outcomes of women of color.

In our analysis, we find that the most disadvantaged group is Hispanic women, who are $5.3 \%$ more likely to be higher likelihood - as compared to White men, based on an upper-bound unemployment definition; and Hispanic men have the smallest disproportionate unemployment probability compared to White men, with a $2.3 \%$ higher likelihood. We further unemployed - followed by Black women, who have $4.4 \%$ 
find that working in an industry with highly teleworkable jobs does not spare Hispanic women and Black women from disproportionate job losses. Hispanic women working in industries with a high degree of ability to work from home are $7 \%$ more likely, and Black women are 6\% more likely, to become unemployed compared to White men. It appears that the pandemic is affecting the already built-in racial/ethnic and gendered structural disparities in the labor market in an even more pronounced way, especially for women of color. As we control for industry and occupation categories, which has been suggested as the one of the main mechanisms through which recessions disproportionately impact demographic groups' unemployment, the remaining differences suggest the role of unobservable factors, including discrimination.

We know from the existing literature that discrimination in hiring and firing practices has been identified as a source of unemployment of Black workers, as it fits into a "last-hired, first-fired" pattern. Empirical studies testing the existence of this pattern during previous recessions showed that beyond layoffs based on observable characteristics, a discriminating employer can lay off equally qualified Blacks and not face economic costs for doing so during downturns (Couch and Fairlie 2010). In the current recession, this effect might have been disadvantageous to Hispanic and Black women. Discrimination is also suggested to cause lower probability of on-the-job-training for women, rendering them more expandable during layoffs (Royalty 1996). To the extent that this effect is larger for women of color, this could explain the higher probability of being laid off during the COVID-19 recession. As more data become available, combined with more qualitative studies, we might be able to understand the additional hardship experienced by women and minorities during the COVID-19 pandemic.

A crucial aspect of the current recession that is affecting the labor supply decisions of mothers and single parents is the ongoing childcare crisis in the USA due to the closure of daycare centers and schools since March 2020. For dualearner heterosexual parents, the already existing unequal distribution of time spent on child-care is likely to be exacerbated by the pandemic. This increased time strain on women and single parents is likely to result in women leaving employment and even exiting the labor force. ${ }^{14}$ The results of the US Census Bureau's Household Pulse Survey Phase II, conducted in July 2020, already show that one in five working-age adults states the reason they were not working was because COVID-19 disrupted their childcare arrangements. Of those not working, women ages 25-44 are almost three times as likely as men to not be working due to childcare demands. Since our emphasis in this work is on the unemployment probability for

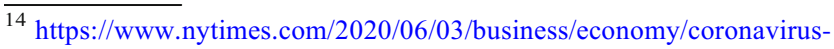
working-women.html
}

intersectional groups, our sample does not include individuals who exit the labor force due to childcare responsibilities. ${ }^{15}$ As time use data become available in the future, researchers will be able to explore the impact of the COVID-19 recession specifically on mothers' time allocation among unpaid and paid work.

Another reason for the higher probability of unemployment for people of color could be the relative difficulty minorityowned businesses have experienced in securing Paycheck Protection Program (PPP) loans. These loans are designed to provide an additional incentive for small businesses to keep their employees on payroll during this recession, and although we do not have any access to data showing who received PPP loans, several surveys conducted by various NGOs point to Black and Latinx small businesses having difficulty receiving these loans. UnidosUS, for example, reports that only 1 in 10 minority-owned businesses was able to get the funds they asked for. ${ }^{16}$

In addition to PPP loans, a federally legislated fiscal impetus program, the CARES Act passed in March 2020, provided Economic Impact Payments to American households of up to $\$ 1200$ per adult for individuals whose income was less than $\$ 99,000$. As the US unemployment rate now stands at $11.1 \%$, it is obvious that this one-shot stimulus payment will not be enough for women and minority workers to maintain their livelihoods. Under the CARES Act, the Pandemic Unemployment Compensation program added a $\$ 600$ weekly boost to unemployment insurance payments, but this was terminated at the end of July 2020. Given that minorities and women are disproportionately affected by this recession, and Black, Latinx, and low-income households have less access to liquid assets (Ganong et al. 2020), the question remains as to how these workers have weathered the expiration of this program. ${ }^{17}$ In our opinion, a revitalization of this program is critical for the well-being of the minority population and women.

\section{Compliance with Ethical Standards}

Conflict of Interest The authors declare that they have no conflict of interest.

\footnotetext{
${ }^{15}$ A recent study by Heggeness (2020) uses monthly panel data from the CPS to compare labor market attachment, non-work activity, hours worked, of those in areas with early school closures and stay-in-place orders with those in areas with delayed or no pandemic closures. While there was no immediate impact on detachment or unemployment, she finds mothers with jobs in early closure states were $53.2 \%$ more likely than mothers in late closure states to have a job but not be working as a result of early shutdowns.

${ }^{16} \mathrm{https}$ ://www.unidosus.org/about-us/media/press/releases/051820UnidosUS-Press-Release-COVID-19-Survey-Black-and-Latino-SmallBusiness

${ }^{17}$ https://equitablegrowth.org/wp-content/uploads/2020/07/072120-ui-workdisincentives-fs.pdf
} 


\section{References}

Adams-Prassl A, Boneva T, Golin M, Christopher R. Inequality in the impact of the coronavirus shock: evidence from real-time surveys. CEPR Discussion Paper No. DP14665. 2020. Available at https:// ssrn.com/abstract=3594297. Accessed 27 June 2020.

Alon T, Doepke M, Olmstead-Rumsey J, and Tertilt M. The impact of COVID-19 on gender equality. NBER Working Paper \#26947. 2020. Available at http://www.nber.org/papers/w26947. Accessed 27 June 2020.

Altonji JG, Blank RM. Race and gender in the labor market. Handb Labor Econ. 1999;3: Chapter 48.

Bartik A, Cullen Z, Glaeser E, Luca M, Stanton C. What jobs are being done at home during the Covid-19 crisis? Evidence from firm-level surveys. NBER Working Paper, \#27422. 2020. Available at https:// www.nber.org/papers/w27422. Accessed 20 July 2020.

Bell E, Nkomo S. Our separate ways: black and white women and the struggle for professional identity. Boston: Harvard Bus. Sch. Press; 2001.

Blau, F. \& A. Winkler. 2017. The economics of women, men, and work. Oxford University Press. 8th edition.

Bradbury K 2000. "Riding tides in the labor market: to what degree do expansions benefit the disadvantaged?" New England Economic Review May-June:3-33.

Browne I, editor. Latinas and African American Women at Work: Race, Gender and Economic Inequality, New York: Russell Sage Foundation; 1999.

Browne I, Misra J. The intersection of gender and race in the labor market. Annu Rev Sociol. 2003;29(1):487-513.

Browne I, Tigges L, Press J. Inequality through labor markets, firms, and families: intersection of gender, race-ethnicity across three cities. In: O'Connor A, Tilly C, Bobo L, editors. Urban Inequality Evidence from Four Cities. New York: Russel Sage Found; 2001. p. 372-406.

Brynjolfsson E, Horton J, Ozimek A, Rock D, Sharma G, TuYe H. "Covid-19 and remote work: an early look at us data." NBER Working Paper \#27344. 2020. Available at https://www.nber.org/ papers/w27344

BLS. The employment situation - April 2020. 2020. https://www.bls. gov. Accessed 17 May 2020.

Cajner T, Radler T, Ratner D, Vidangos I. Racial gaps in labor market outcomes in the last four decades and over the business cycle. In: Finance and Economics Discussion Series 2017-071. Washington: Board of Governors of the Federal Reserve System; 2017. https:// doi.org/10.17016/FEDS.2017.071.

Couch K, Fairlie R. Last hired, first fired? Black-white unemployment and the business cycle. Demography. 2010;47(1):227-47 Available at www.jstor.org/stable/25651498.

Couch KA, Fairlie R, and Xu H. Racial differences in labor market transitions and the Great Recession. IZA Discussion Paper No. 9761. 2016. Available at SSRN: https://ssrn.com/abstract $=2742549$. Accessed 22 June 2020.

Cowan B. Short-run effects of Covid-19 on U.S. worker transitions. NBER Working Paper \#27315. 2020. Available at http://www. nber.org/papers/w27315. Accessed 22 July 2020.

Dingel $\mathrm{J}$ and NeimanB. How many jobs can be done at home? NBER Working Paper \#26948. April 2020. 2020 Available at https://www. nber.org/papers/w26948. Accessed 22 July 2020.

Engemann K, Wall HJ. "The effects of recessions across demographic groups" 2009. available at SSRN: https://ssrn.com/abstract= 1490041 or https://doi.org/10.2139/ssrn.1490041.
Fairlie R and Couch $\mathrm{K}$ and Xu H. "The impacts of Covid-19 on minority unemployment: first evidence from April 2020 CPS Microdata." NBER Working Paper \#27246. 2020 Available at https://www. nber.org/papers/w27246

Freeman RB. Changes in the labor market for black Americans, 1948-72. Brook Pap Econ Act. 1973;1973(1):67-120.

Ganong P, Jones D, Noel PJ, Greig FE, Farrell D and Wheat C. Wealth, race, and consumption smoothing of typical income shocks. NBER Working Paper \#27552. 2020. Available at https://www.nber.org/ papers/w27552. Accessed 29 July 2020.

Grown C, Tas E. Gender equality in U.S. labor markets in the "Great Recession" of 2007-10. In: Starr MA, editor. Consequences of economic downturn. New York: Perspectives from Social Economics. Palgrave Macmillan; 2011. https://doi.org/10.1057/ 97802301183559.

Gupta A. Why some women call this recession a 'Shecession.' New York Times. 2020 Available at: https://www.nytimes.com/2020/05/09/us/ unemployment-coronavirus-women.html. Accessed 22 July 2020.

Heggeness ML. Estimating the immediate impact of the COVID-19 shock on parental attachment to the labor market and the double bind of mothers. Federal Reserve Bank of Minneapolis, Institute Working Paper 33. 2020.

Hoynes H and Miller D, Schaller J. "Who suffers during recessions?" NBER working paper \#17951. 2012 March 2012. Available at https://www.nber.org/papers/w17951

Kondo A 2015. "Differential effects of graduating during a recession across gender and race" in IZA Journal of Labor Economics.

McNicholas $\mathrm{C}$ and Poydock M. Who are essential workers? Economic policy institute working economics blog. 2020. Available at https:// www.epi.org/blog/who-are-essential-workers-a-comprehensivelook-at-their-wages-demographics-and-unionization-rates/. Accessed 22 July 2020.

Montenovo L, Jiang X, Lozano-Rojas F, Schmutte I, Simon K, Weinberg B, Wing C. Determinants of disparities in Covid-19 job losses. NBER Working Paper \#27132. 2020. Available at https://www. nber.org/papers/w27132. Accessed 22 July 2020.

Paul M, Zaw K, Hamilton D and Darity W. Returns in the labor market: A nuanced view of penalties at the intersection of race and gender. Washington Center for Equitable Growth Working Paper Series. 2018. Available at: https://equitablegrowth.org/working-papers/ intersectionality-labor-market/. Accessed 22 July 2020.

Rho H \& Brown H, \& Fremstad S. 2020. A basic demographic profile of workers in frontline industries. CEPR Publications. 2020. Available at https://cepr.net/a-basic-demographic-profile-of-workers-infrontline-industries/. Accessed 22 July 2020.

Rosen S. The theory of equalizing differences. In: Ashenfelter O, Layard R, editors. Handb Labor Econ. Amserdam: North-Holland; 1986.

Royalty $\mathrm{AB}$. The effects of job turnover on the training of men and women. Ind Labor Relat Rev. 1996;49(3):506-21.

Weber L. Understanding race, class, gender, and sexuality: a conceptual framework. Boston: McGraw Hill; 2001.

Yasenov V. Who can work from home? IZA Discussion Paper No. 13197. 2020. Available at https://www.iza.org/publications/dp/ 13197/who-can-work-from-home

Publisher's Note Springer Nature remains neutral with regard to jurisdictional claims in published maps and institutional affiliations. 